\title{
ARS GRÁFICA
}

Marcelo Shellini

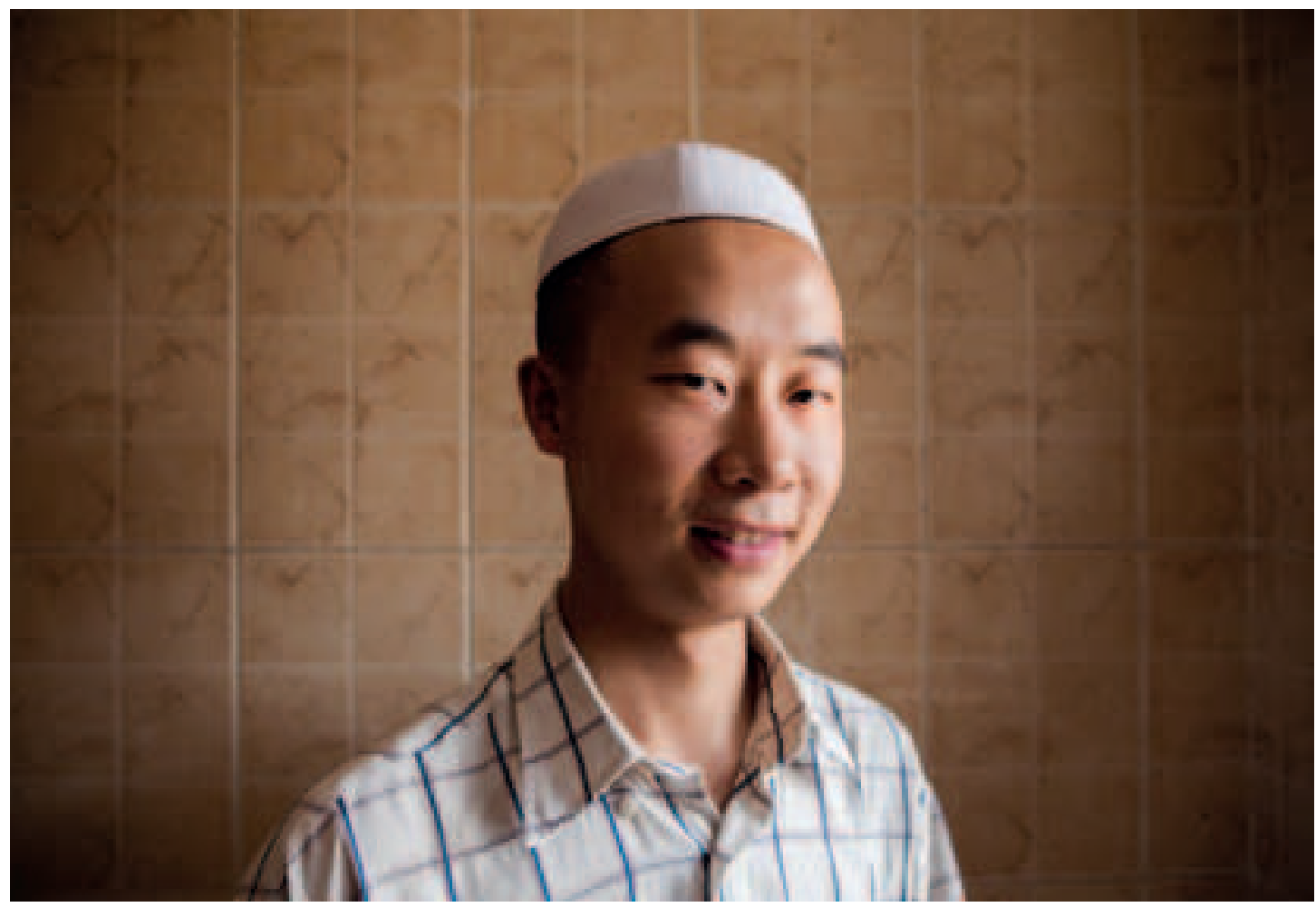




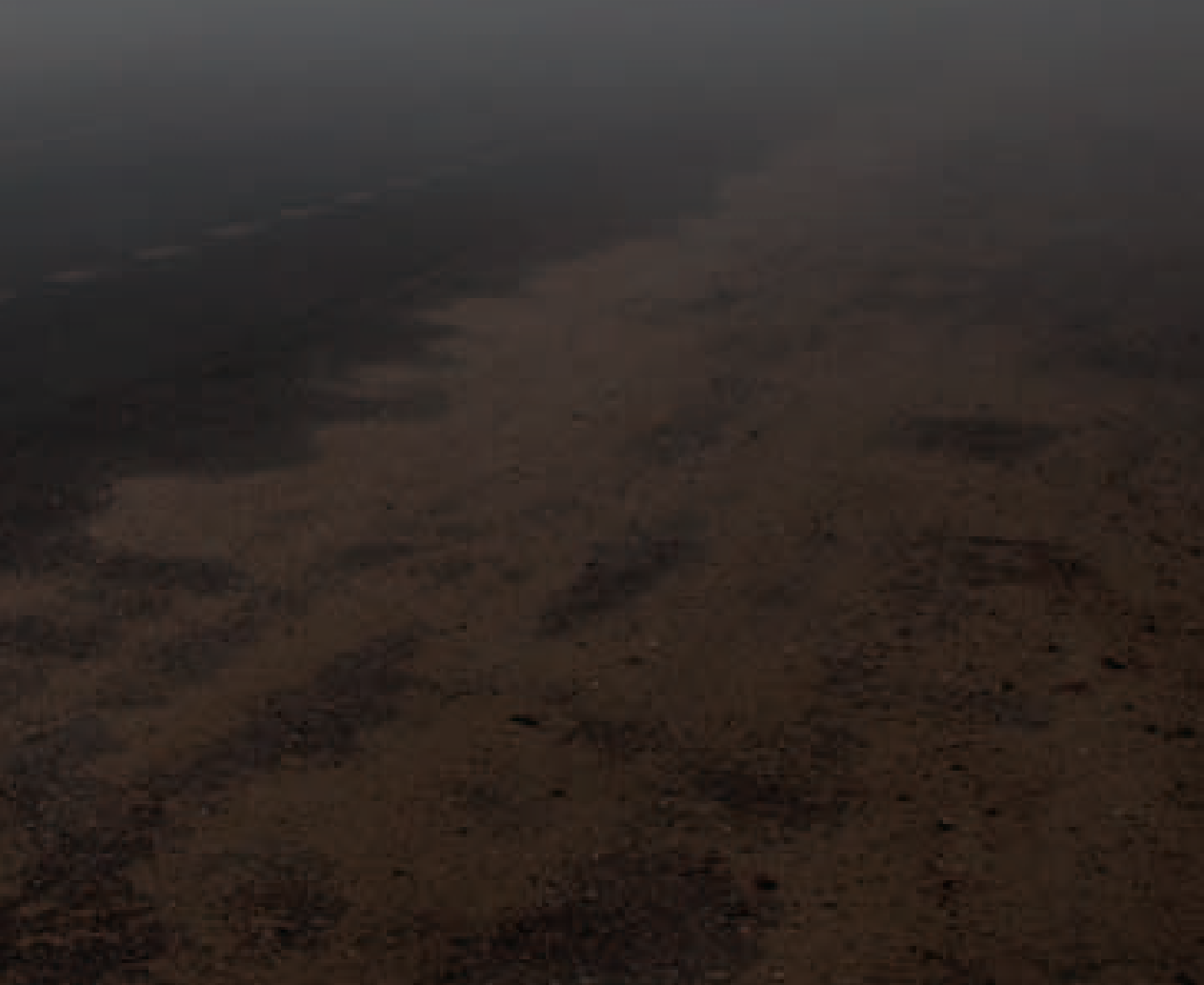


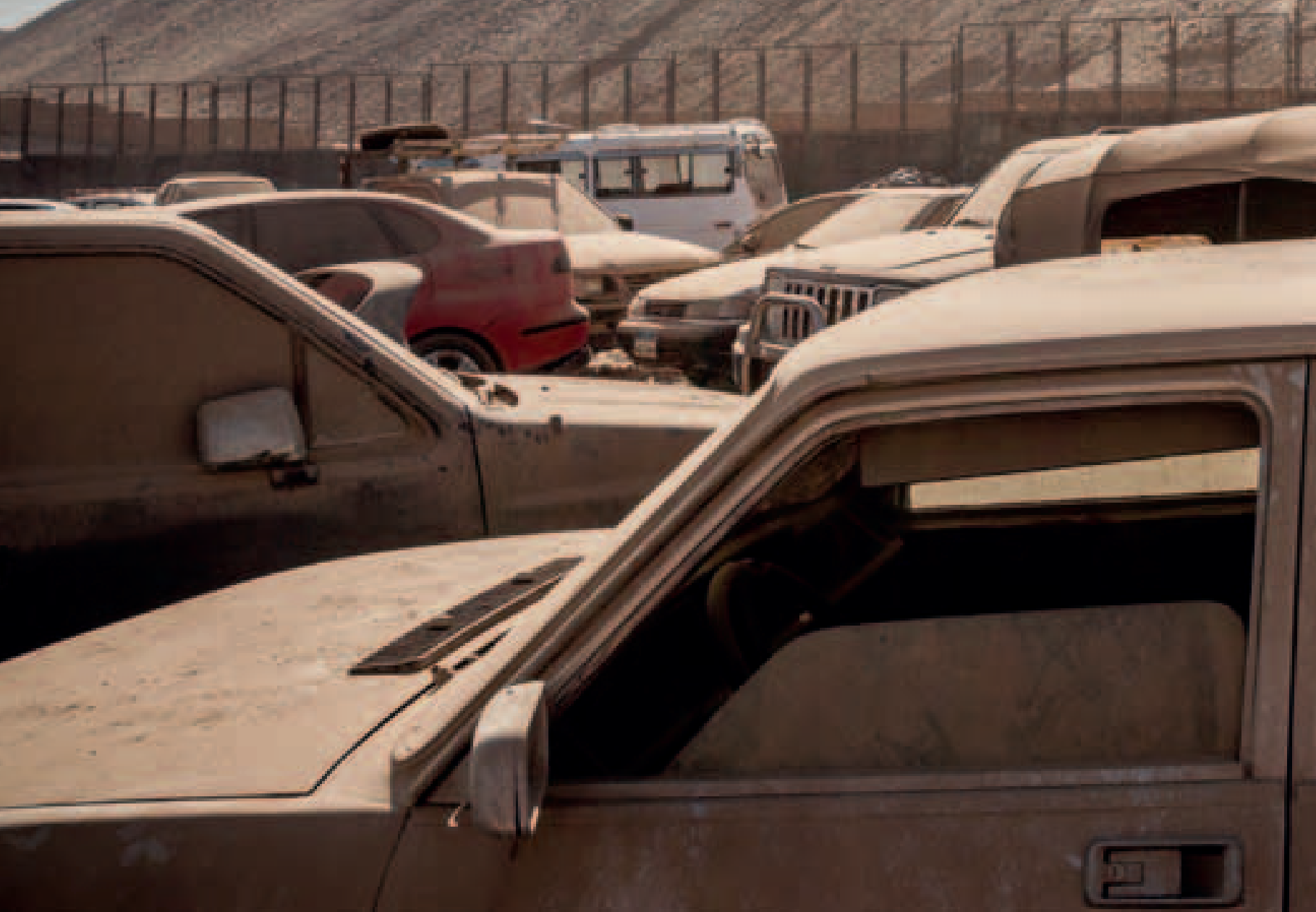




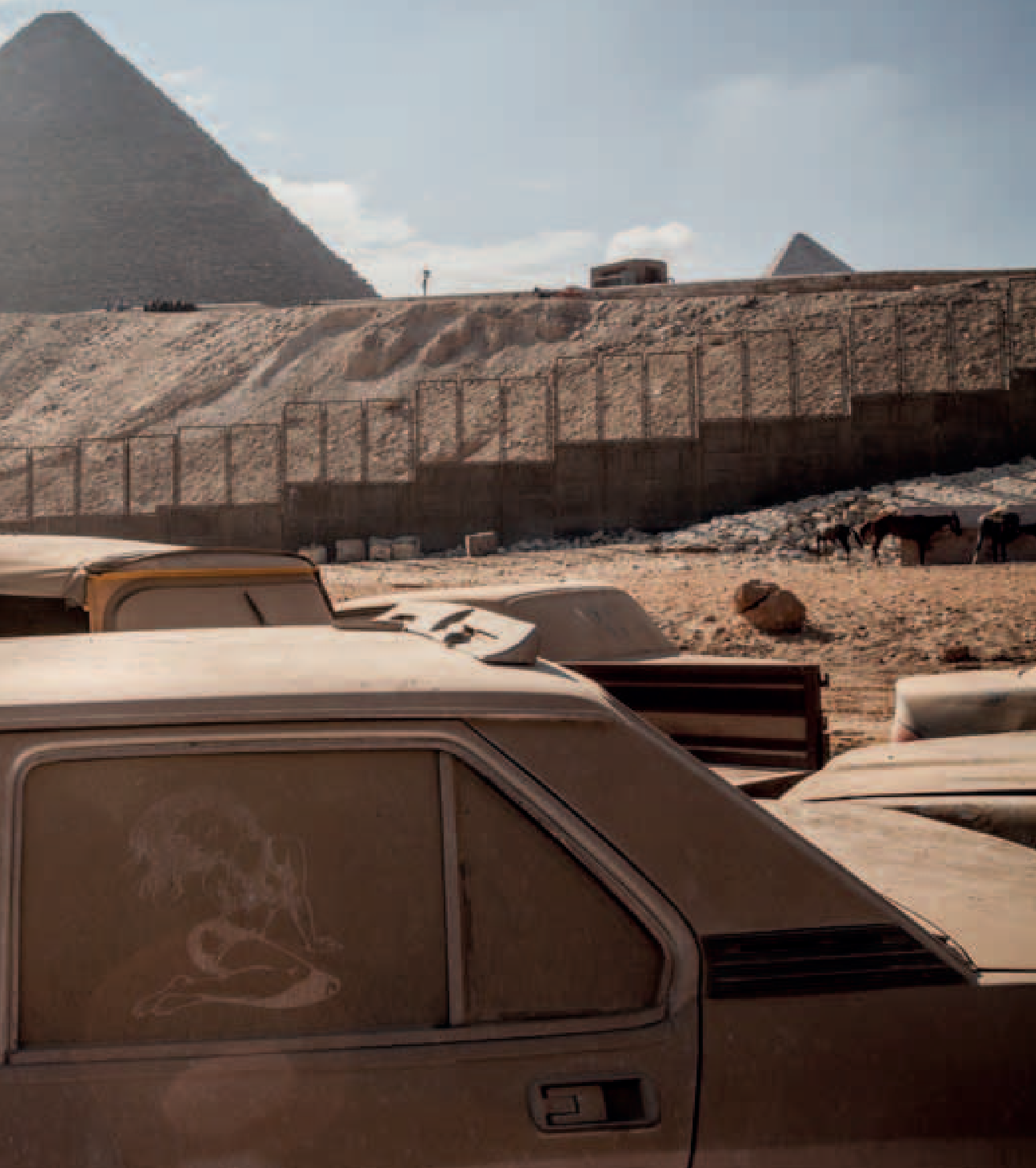




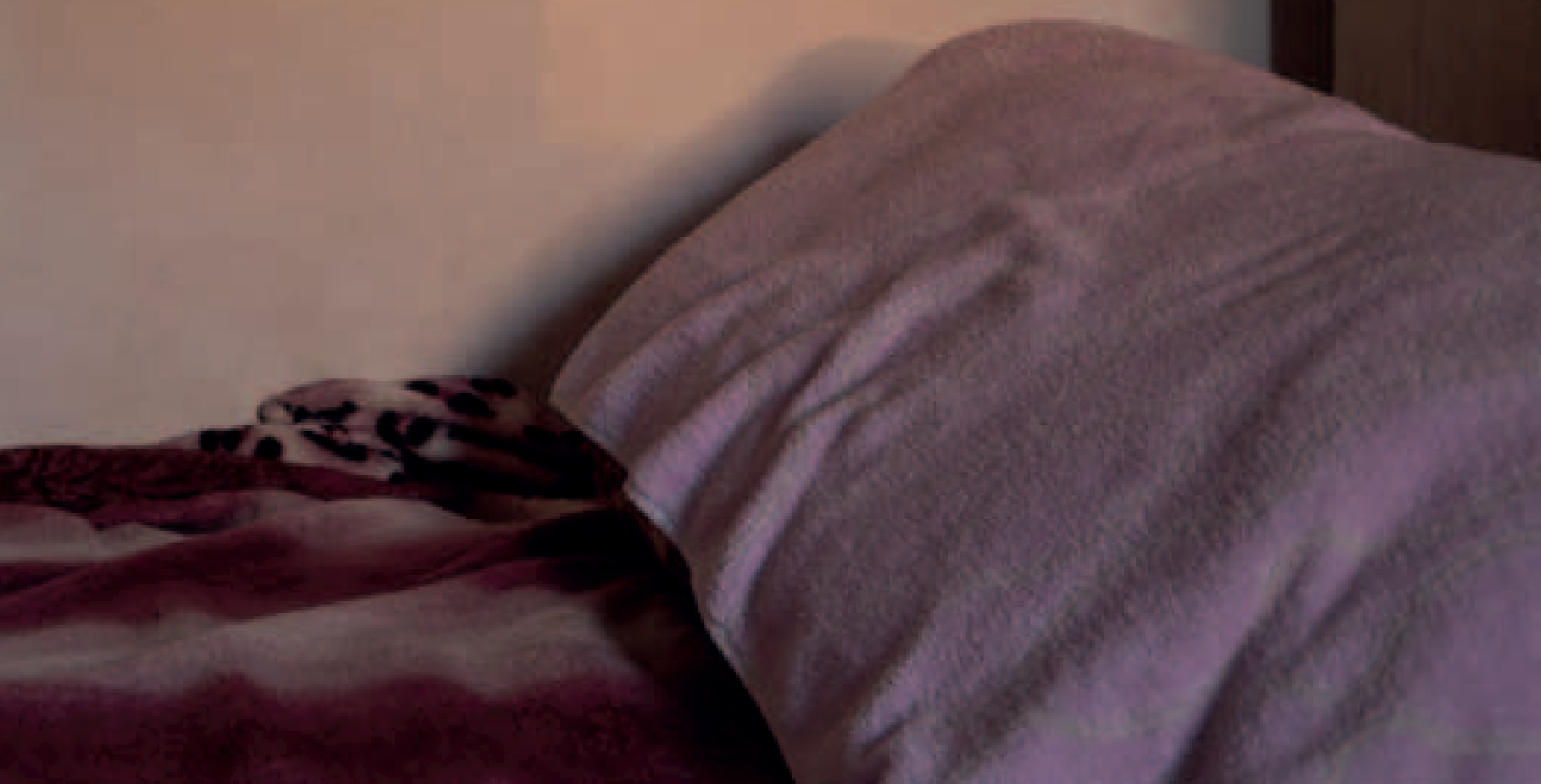




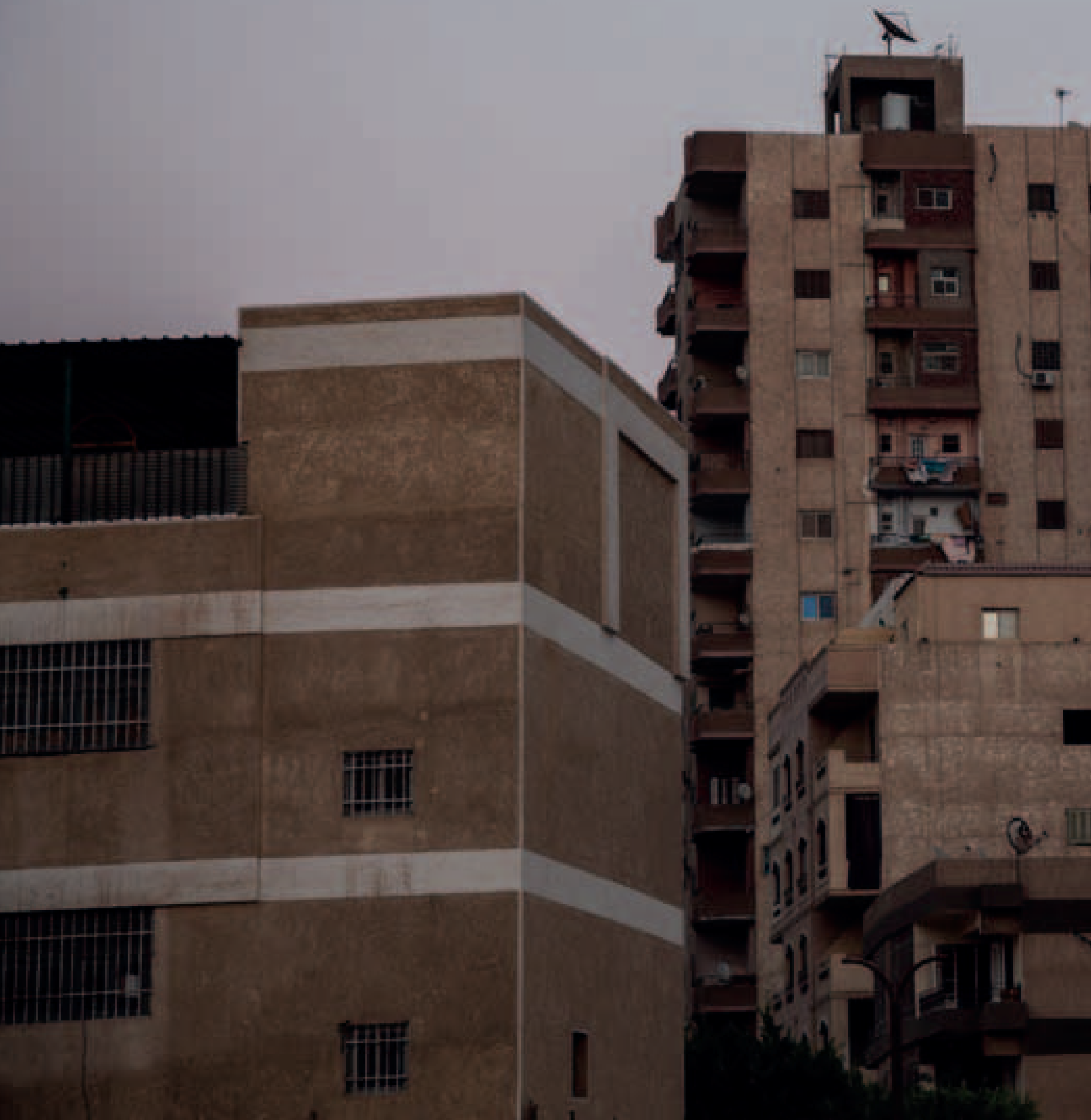




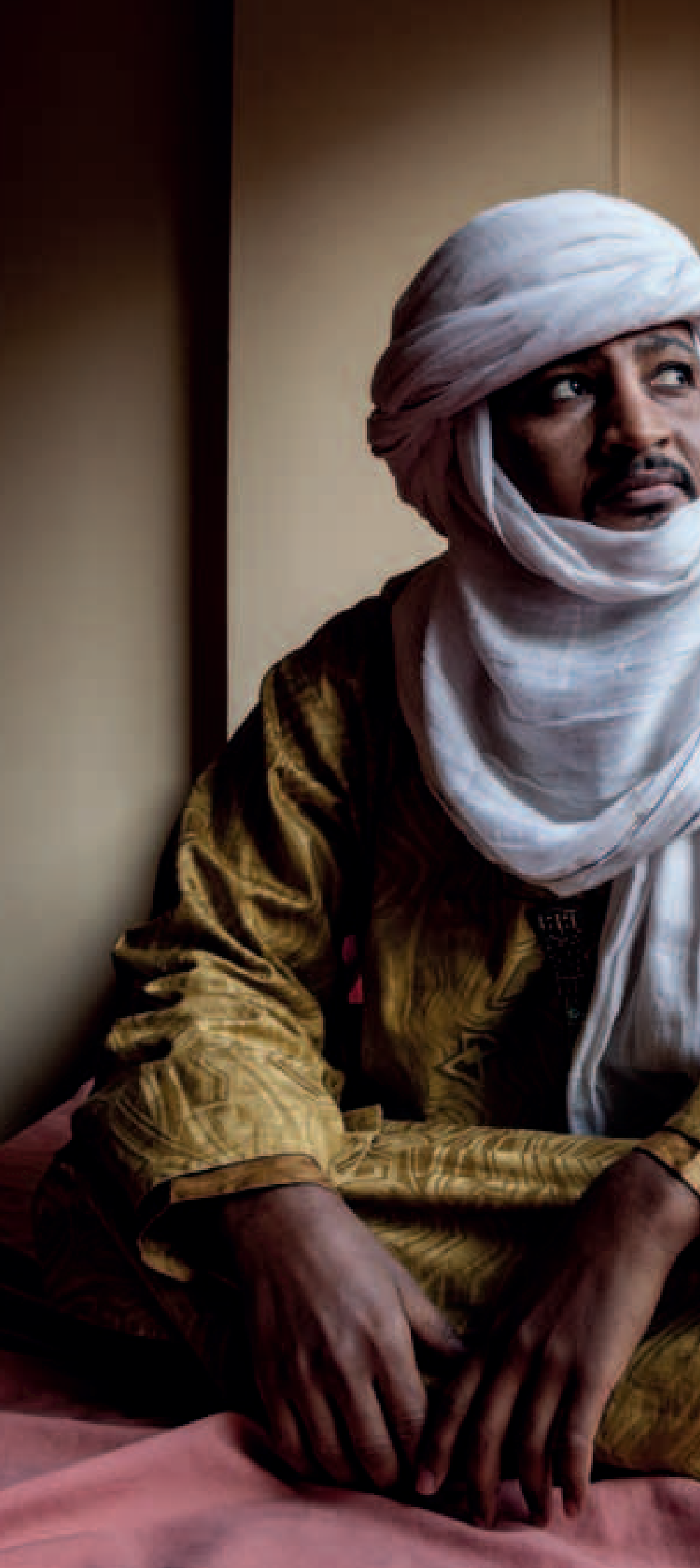



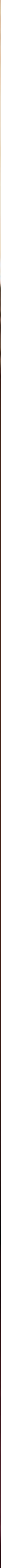


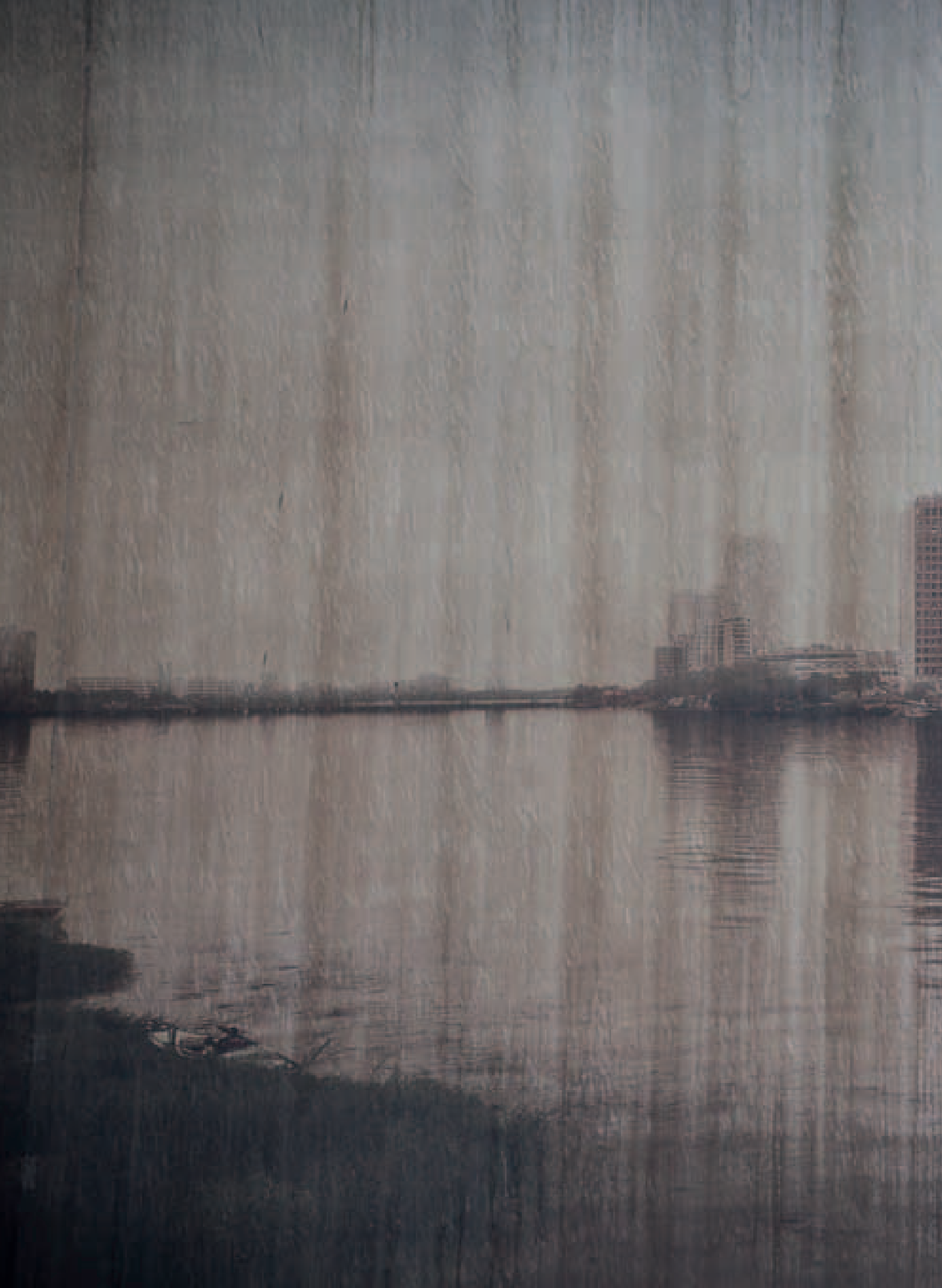




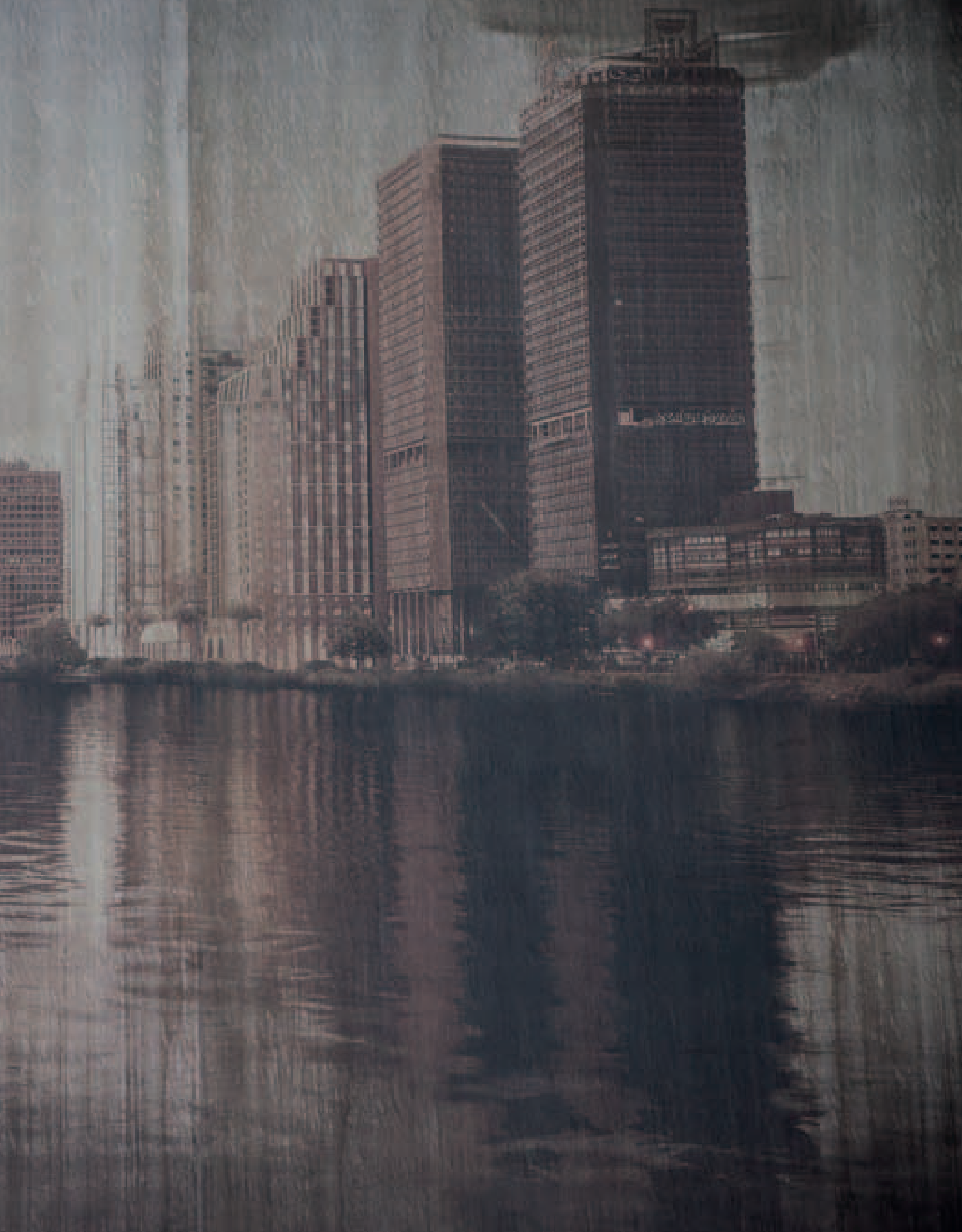




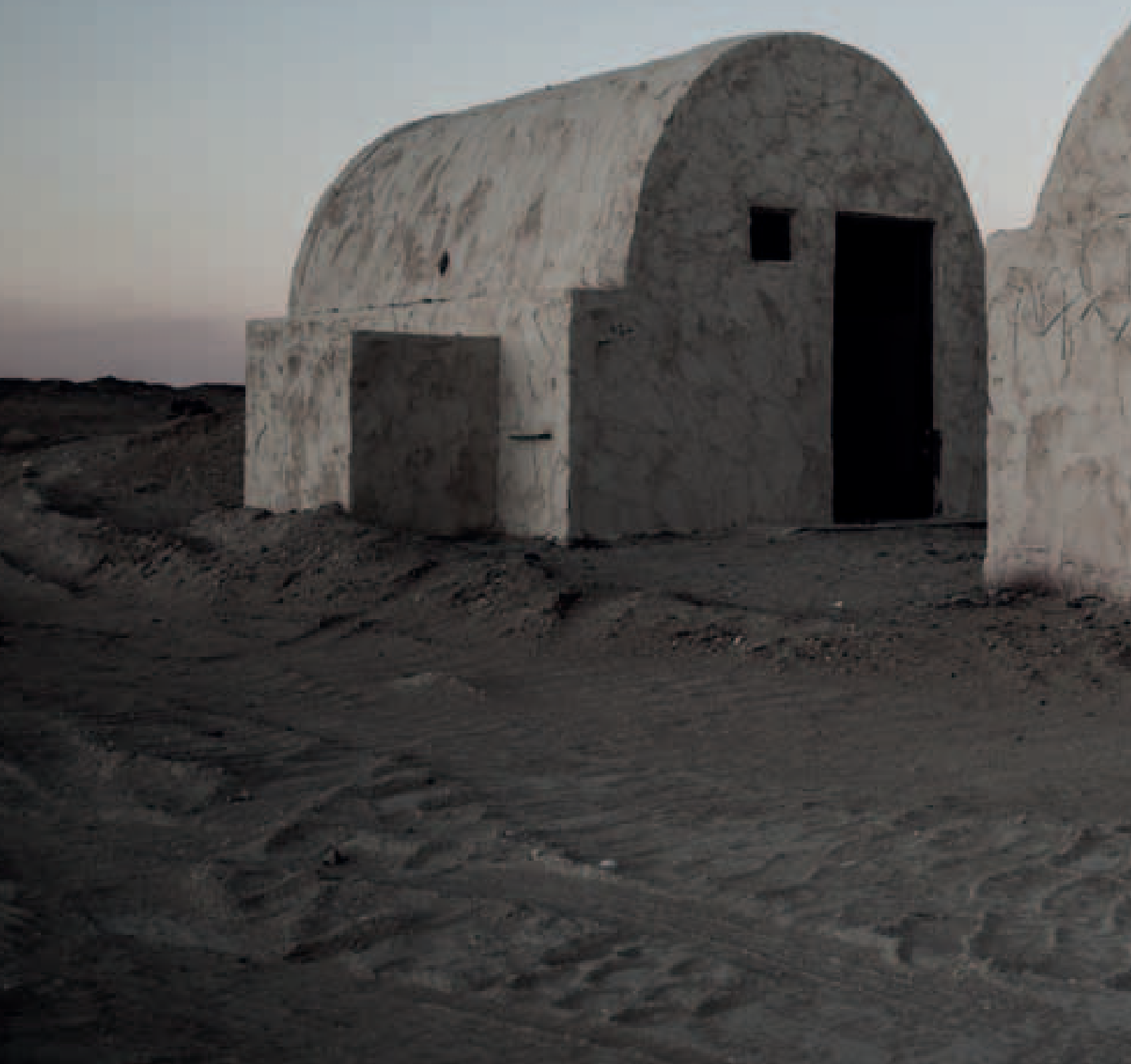




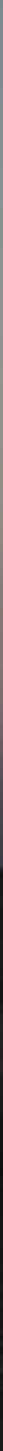




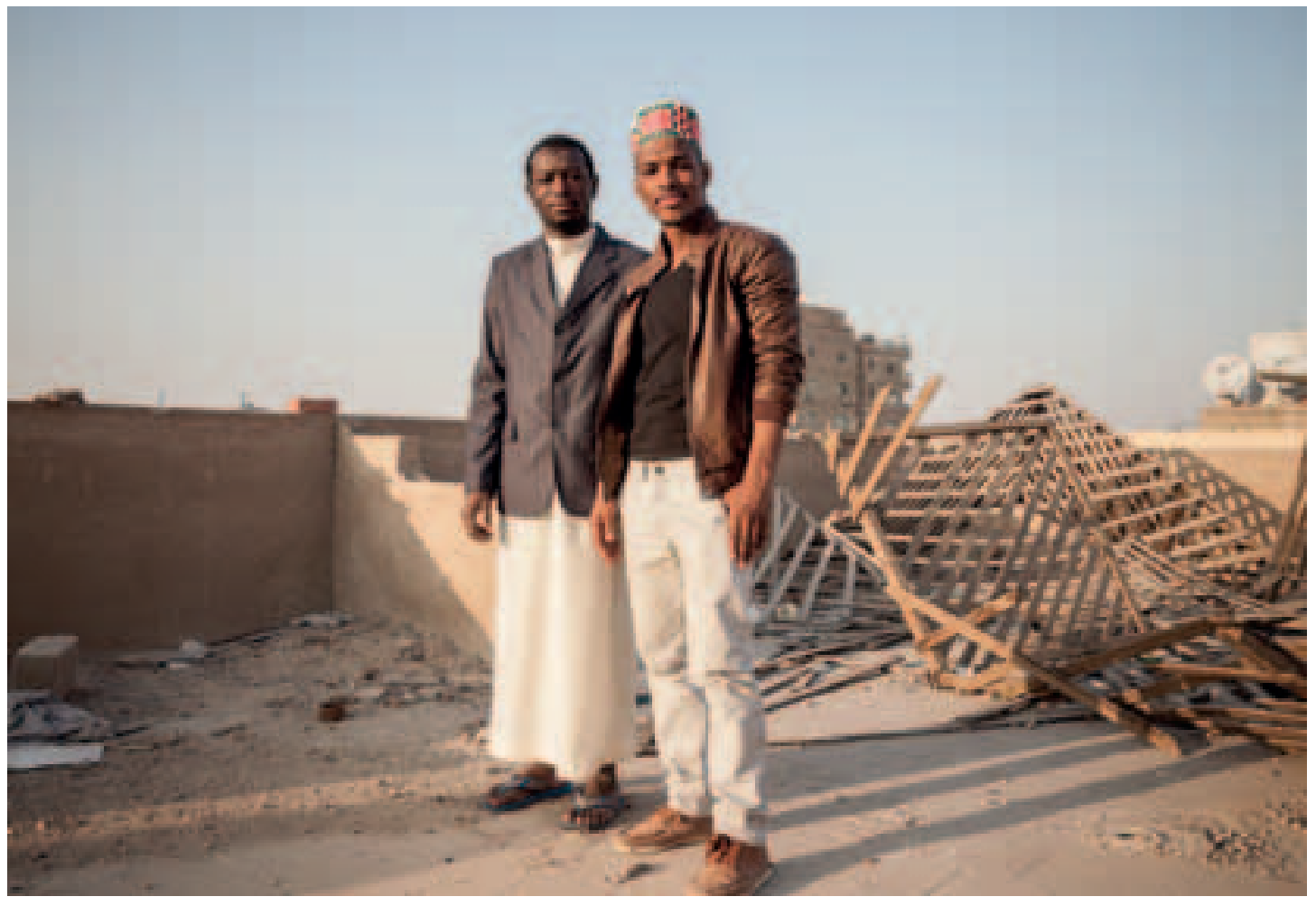

